\title{
MINERALOGY, PETROGRAPHY, AND OXYGEN ISOTOPIC COMPOSITIONS OF ULTRAREFRACTORY INCLUSIONS FROM CARBONACEOUS CHONDRITES.
} \section{A. N. Krott ${ }^{1,2 *}$, C. $\mathrm{Ma}^{3}$, K. Nagashima ${ }^{1}$, A. M. Davis ${ }^{4,5,6}$, J. R. Beckett ${ }^{3}$, S. B. Simon ${ }^{7}$, M. Komatsu ${ }^{8}$, T. J. Fagan ${ }^{9}$ P.} T. Genzel ${ }^{2}$, F. Brenker ${ }^{2}$, M. A. Ivanova ${ }^{10}$, and A. Bischoff ${ }^{11}$

${ }^{1}$ University of Hawai ‘i at Mānoa, USA, *sasha@ higp.hawaii.edu; ${ }^{2}$ Goethe University, Germany; ${ }^{3}$ California Institute of Technology, USA; ${ }^{4}$ Department of the Geophysical Sciences, ${ }^{5}$ Enrico Fermi Institute, ${ }^{6} \mathrm{Chicago}$ Center for Cosmochemistry, The University of Chicago, USA; ${ }^{7}$ University of New Mexico, USA; ${ }^{8}$ The Graduate University for Advanced Studies, Japan; ${ }^{9}$ Waseda University, Japan; ${ }^{10}$ Vernadsky Institute of Geochemistry of Russian Academy of Sciences, Russia; ${ }^{11}$ Institut für Planetologie, Germany

Introduction: Fine-grained CAIs with Group II rare earth element (REE) patterns condensed from a gaseous reservoir from which the ultrarefractory (UR) REEs had been removed. The carriers of UR REEs are poorly known. Here we report on the mineralogy, petrography and O-isotope compositions of 25 CAIs, presumably UR (REEs have not yet measured), from CR2, CM2, C3.0, CO3.0-3.6, CV3.1-3.6, and CH3.0 carbonaceous chondrites (CCs).

Mineralogy and Petrography: The UR CAIs studied are dominated by $\mathrm{Zr}, \mathrm{Sc}$, Ti, and Y-rich oxides (allendeite, kangite, lakargite, panguite, Y-perovskite, tazheranite, warkite, zirconolite) and silicates (davisite, eringaite, thortveitite) and often contain refractory metal alloy nuggets; most are surrounded by rims of Sc-pyroxene, \pm eringaite, Al,Tidiopside, and \pm forsterite. These CAIs occur as ( $i$ ) individual objects, (ii) constituents of amoeboid olivine aggregates and Fluffy Type A CAIs, and (iii) relict objects in forsterite-bearing Type B CAIs and chondrules.

Oxygen-isotope compositions: Nearly all UR CAIs from the least metamorphosed CCs [Murchison (CM2), Y793261 (CR2), Acfer 182 (CH3.0), and DOM 08006 (CO3.0)] have uniform O-isotope compositions $\left(\Delta^{17} \mathrm{O} \sim-24 \pm 2 \%\right.$ \% and $\sim-6 \pm 2 \%$ ) (Fig. 1a,b). In contrast, most UR CAIs from CCs of petrologic type $\geq 3.1$ (CVs: Kaba, Vigarano, Efremovka, and NWA 3118, and COs: DOM 08004, Moss, and Ornans) are isotopically heterogeneous: spinel, hibonite and forsterite are ${ }^{16} \mathrm{O}$-rich $\left(\Delta^{17} \mathrm{O} \sim-24 \%\right)$, but warkite, eringaite, kangite, Y-perovskite, and davisite are ${ }^{16} \mathrm{O}-$

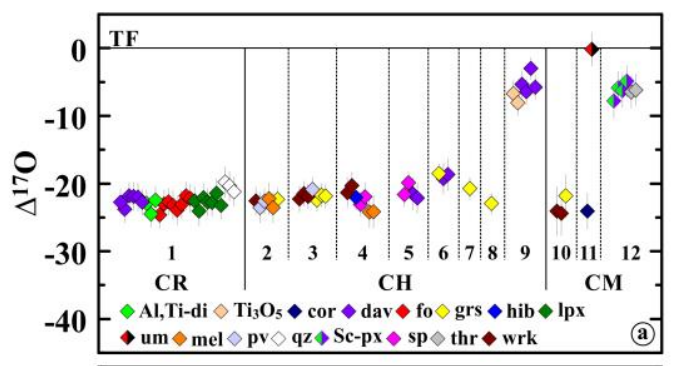
depleted to various degrees (Fig. $1 \mathrm{~b}, \mathrm{c}$ ).

Figure 1. $\Delta^{17} \mathrm{O}\left(=\delta^{17} \mathrm{O}-0.52 \times \delta^{18} \mathrm{O}\right)$ of UR CAIs from (a) $\mathrm{CM} 2$, CR2, and CH3.0 chondrites; (b) CO3.0-3.6 chondrites and Acfer 094 (C3.0 ungrouped); (c) CV3 chondrites. $1=4$ from Y-793261; $2=5-2$ from NWA 470; $3=418 / P$ from Acfer 182; $4=1573-1$ from Acfer 214; $5=35$ from ALH 85085; $6=6$ from PCA 91326; $7=3$ from PCA 91452; $8=M B$ 111-1 from Acfer 214; $9=A 0031$ from SaU 290; $10=M 11 ; 11=$ M80-1; $12=$ M10 from Murchison; $13=100-1$ from DOM $08006(\mathrm{CO} 3.0) ; 14=22-4$ and $15=Y Y$ from DOM $08004(\mathrm{CO} 3.1) ; 16=$ Oscar from Ornans $(\mathrm{CO} 3.4) ; 17=1$

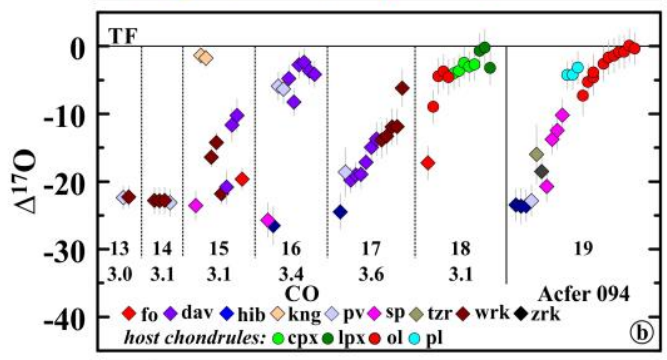
from Moss (CO3.6); $18=50-1$ from MAC 88107; $19=17$ from Acfer 094; $20=V 3,21=V 7$, and $22=V 13$ from Vigarano; $23=$ $3 \mathrm{~N}$ from NWA 3118; $24=33 E$ from Efremovka; $25=A l-2$ from Allende. Abbreviations: Al,Ti-di $=$ Al,Ti-diopside; cor $=$ corundum; $\mathrm{cpx}=$ Sc-bearing high-Ca pyroxene dav = davisite; er $=$ eringaite; fo = forsterite; grs = grossite; hib = hibonite; kng = kangite; $\mathrm{lpx}=$ Sc-bearing low-Ca pyroxene; $\mathrm{um}=$ unidentified $\mathrm{Sc}-, \mathrm{Zr}-$, and Y-rich oxide; mel $=$ melilite $; \mathrm{ol}=\mathrm{Fe}-\mathrm{Mg}$ olivine $; \mathrm{pl}=$ plagioclase; $\mathrm{pv}=$ perovskite; $\mathrm{qz}=$ quartz; Sc-px = Sc-bearing Al,Ti-diopside;

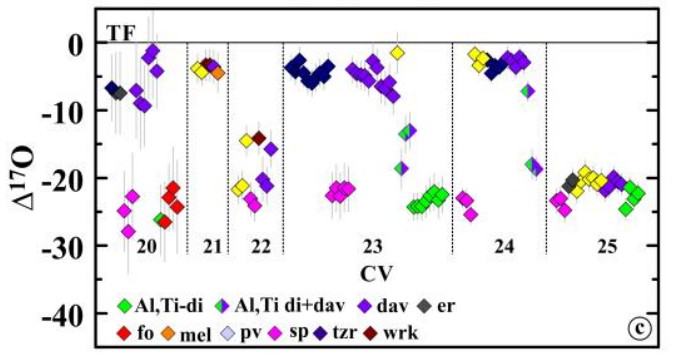
$\mathrm{sp}=$ spinel; $\mathrm{TF}=$ terrestrial fractionation line; $\mathrm{thr}=$ thortveitite; $\mathrm{Ti}_{3} \mathrm{O}_{5}=\mathrm{Sc}$-rich $\mathrm{Ti}_{3} \mathrm{O}_{5} ; \mathrm{tzr}=$ tazheranite; wrk $=$ warkite; zrk = zirkelite. Diamonds and circles indicate minerals in CAIs and host chondrules, respectively.

Discussion: Most UR CAIs formed in a ${ }^{16} \mathrm{O}$-rich gaseous reservoir; some subsequently experienced incomplete melting and $\mathrm{O}-$ isotope exchange in the CAI- and chondrule-forming regions. UR CAIs from CCs of petrologic type 2-3.0 largely retained their original O-isotope compositions, whereas those from $\mathrm{CV}$ and $\mathrm{CO}$ chondrites of higher petrologic type that experienced fluid-assisted thermal metamorphism, recorded mineralogically-controlled O-isotope exchange mostly with a ${ }^{16} \mathrm{O}$-depleted aqueous fluid on the host chondrite parent asteroids. UR CAIs melted during chondrule formation (CAIs 18 and 19 in Fig. 1b) and possibly a relict UR CAI in a FoB CAI (CAI 23 in Fig. 1c) appear to have experienced O-isotope exchange with a ${ }^{16} \mathrm{O}$-depleted nebular gas during melting. 